\title{
Glucose restriction combined with chemotherapy decreases telomere length and cancer antigen-125 secretion in ovarian carcinoma
}

\author{
STEPHANIE ANTOUN ${ }^{1}$, DAVID ATALLAH ${ }^{2}$, ROULA TAHTOUH $^{1}$, MONA DIAB ASSAF $^{3}$, \\ MALAK MOUBARAK ${ }^{2}$, ELIANE NASSER AYOUB ${ }^{4}$, GEORGES CHAHINE ${ }^{5}$ and GEORGE HILAL $^{1}$ \\ ${ }^{1}$ Cancer and Metabolism Laboratory, Faculty of Medicine, Saint Joseph University, Beirut 1107 2180; \\ ${ }^{2}$ Department of Obstetrics and Gynecology, Hotel-Dieu De France Hospital, Beirut 16-6830; \\ ${ }^{3}$ Pharmacology and Cancerology Laboratory, Faculty of Sciences, Lebanese University, Beirut 6573/14; \\ Departments of ${ }^{4}$ Anesthesiology and ${ }^{5}$ Oncology, Hotel-Dieu De France Hospital, Beirut 16-6830, Lebanon
}

Received June 3, 2019; Accepted October 3, 2019

DOI: $10.3892 / \mathrm{ol} .2019 .11233$

\begin{abstract}
Although chemotherapy is the standard treatment for ovarian cancer (OC), recent studies have focused on its coupling with hypoglycemic drugs to decrease glucose availability. Similarly to cancer antigen 125 (Ca-125), telomerase, the key protein for telomere lengthening, is overexpressed in $90 \%$ of OC cases. The aim of the present study was to investigate the effect of the combination of glucose restriction and chemotherapy on telomere length and $\mathrm{Ca}-125$ secretion in OC cells. SKOV-3, OVCAR-3 and Igrov-1 cells were treated with $20 \mu \mathrm{M}$ cisplatin and $100 \mathrm{nM}$ paclitaxel for $48 \mathrm{~h}$ in three different glucose concentrations: i) $4.5 \mathrm{~g} / \mathrm{l}$, ii) $1 \mathrm{~g} / 1$ and iii) $0.5 \mathrm{~g} / \mathrm{l}$. The same treatment was repeated once per week for 6 consecutive weeks. The surviving cells were considered platinum-taxane escape (PTES) cells. The expression levels of telomerase and Ca-125 in treated and PTES cells were quantified by $\mathrm{qPCR}$, and Ca-125 secretion by ELISA. Telomere
\end{abstract}

Correspondence to: Professor George Hilal, Cancer and Metabolism Laboratory, Faculty of Medicine, Saint Joseph University, PO 11-5076 Damascus Road, Riad el Solh, Beirut 1107 2180, Lebanon

E-mail: george.hilal@usj.edu.lb

Abbreviations: BMP2, bone morphogenetic protein 2; Ca-125, cancer antigen 125; CDDP, cisplatin; ERCC1, excision repair cross-complementation group 1; hTERT, human telomerase reverse transcriptase; IL-6, interleukin-6; IL-8, interleukin-8; MAPK, mitogen-activated protein kinase; mTOR, mechanistic target of rapamycin; NK, natural killer; PI3K, phosphatidylinositol-4,5-bisphosphate 3-kinase; PTES, platinum-taxane escape; PTX, paclitaxel; RT-qPCR, reverse transcription-quantitative polymerase chain reaction; siRNA, small interfering RNA

Key words: chemotherapy, glucose restriction, platinum-taxane escape cells, cancer antigen-125, telomerase length was evaluated by qPCR according to the Cawthon method. The modulation of Ca-125 by telomerase was assessed using inhibitors, small interfering RNA and transfection with human telomerase reverse transcriptase (hTERT) vectors. The implication of phosphatidylinositol-4,5-bisphosphate 3-kinase/protein kinase $\mathrm{B} /$ mechanistic target of rapamycin (PI3K/Akt/mTOR) in Ca-125 modulation was investigated using specific inhibitors. An increase in hTERT and Ca-125 expression levels (range, 1.5-3 fold) was observed in short-term treated cells. However, an opposite effect was detected in PTES cells, where the rate of decrease in the expression levels of hTERT and Ca-125 reached $60 \%$ after treatment in $0.5 \mathrm{~g} / 1$ glucose. Moreover, telomere length was decreased by $30 \%$ in cells treated with $0.5 \mathrm{~g} / 1$ glucose. Inhibition of hTERT expression significantly decreased Ca-125 secretion, suggesting a potential modulation of Ca-125 by hTERT. The inhibition of the PI3K/Akt/mTOR pathway also decreased Ca-125 secretion; however, the effect of this treatment was not enhanced when coupled with telomerase inhibitors. In conclusion, the combination of chemotherapy and glucose restriction was observed to decrease Ca-125 secretion and telomerase expression leading to shortening in telomere length. Thus, decreasing glucose availability for OC cells during treatment may lead to a better clinical outcome and potentially improve the prognosis of patients with OC.

\section{Introduction}

Ovarian cancer (OC) is one of the most commonly diagnosed types of gynecological cancer worldwide and had the highest mortality rates among all types of cancer of the female reproductive system in 2017 (1). Despite the poorly understood etiology of this cancer type, certain risk factors have been established, which include genetic predisposition and age. By contrast, contraceptive administration and increased parity have been found to be major protective factors (2). The most common subtypes of OC include serous, mucinous, endometrioid and clear cell carcinoma (3). Since OC is asymptomatic during its early stages, it is most commonly diagnosed at late 
stages, leading to a poor prognosis and short overall survival time (4). In total, $>80 \%$ of OC cases exhibit a positive response to standard chemotherapy along with platinum-based and taxane molecules (5); nevertheless, chemoresistance remains a major limitation in cancer treatment (6).

Although cancer antigen $125(\mathrm{Ca}-125)$ is the major biomarker used for diagnosis and disease monitoring in $\mathrm{OC}$, this glycoprotein is also highly expressed in other types of malignancies, including breast cancer, mesothelioma, non-Hodgkin's lymphoma and gastric cancer (7-11), and is less expressed in some benign cases, including pregnancy and ovulatory cycles $(12,13)$. Despite the functions of Ca-125 being poorly understood, certain studies have suggested the implication of this glycoprotein in the cell-mediated immune response. Ca-125 binds to natural killer (NK) cells via galectin-1 and other antibodies, leading to a reduction in CD16 expression and suppression of the NK cell cytotoxic responses $(14,15)$. Moreover, Ca-125 is able to bind to mesothelin, a $40-\mathrm{kDa}$ protein expressed by mesothelial cells and certain types of cancer cells, including epithelial OC cells. Taking into account that peritoneal cells express the membrane-bound form of mesothelin, this interaction between both proteins may increase the risk of metastasis of $\mathrm{Ca}-125$-expressing tumor cells into the peritoneal cavity $(16,17)$. Furthermore, overexpression of the mucin 16 gene coding for $\mathrm{Ca}-125$ has been observed to increase the risk of resistance to certain chemotherapeutic agents, including cisplatin (18). Ca-125, which is modulated by various factors, regulates the activity of mechanistic target of rapamycin (mTOR) kinase, which in turn controls the expression of its downstream target c-MYC. In addition, knockdown of the MUC16 gene in pancreatic cancer cells has been shown to lead to a decrease in glucose uptake and lactate secretion, and to an alteration of cellular proliferation and metabolism (19).

In $>80 \%$ of different types of cancer case, telomerase is expressed by cancer cells to ensure their immortalization (20). This enzyme promotes telomere length stabilization and elongation through de novo synthesis of repeats lost after DNA replication or oxidative stress (21). Recently, inhibitors of telomerase activity, including BIBR1532, have been investigated as potential adjuvants to platinum-based chemotherapy in OC cells in vitro (22). The catalytic subunit of telomerase, human telomerase reverse transcriptase (hTERT), regulates telomerase activity through the variation of its expression (23). In fact, hTERT mRNA expression is regulated by a number of proteins; however, the transcription factor c-MYC serves an essential role in the activation of this expression by forming a complex with the MYC-associated factor X protein and binding to the $\mathrm{E}$ boxes of the promoter region (24). The expression of c-MYC is linked to various signaling pathways, including the phosphatidylinositol-4,5-bisphosphate 3-kinase $(\mathrm{PI} 3 \mathrm{~K}) /$ protein kinase B $(\mathrm{Akt}) / \mathrm{mTOR}, \mathrm{Wnt} / \beta$ catenin and mitogen-activated protein kinase signaling pathways $(25,26)$.

Increased glucose metabolism is a distinct characteristic of highly proliferative cells, including cancer cells, stem cells and immune cells (27). Even in the presence of oxygen, cancer cells tend to metabolize glucose into lactate instead of undergoing oxidative phosphorylation. This process is termed the Warburg effect (28). Since one of the eight hallmark characteristics of cancer cells is their ability to reprogram glucose metabolism (29), the effect of glucose restriction on cancer cell proliferation, apoptosis and response to treatment has been recently studied. In fact, glucose levels in cancer patients may be an important prognostic indicator. In OC, increased expression of glucose transporter 1 (GLUT1), a transmembrane protein responsible for glucose uptake, is related to shorter survival time in patients with OC (30). In addition, decreasing glucose availability for colon cancer cells has been reported to contribute to an increase in cell death (31). Moreover, the combination of glucose restriction and autophagy inhibition has been shown to result in decreased tumor growth and cancer cell proliferation (32). Furthermore, a decrease in telomerase activity and a higher response rate to the telomerase inhibitor BIBR-1532 was observed in breast cancer cells cultured in medium with low glucose concentration (33).

Considering the fact that most relapse cases in patients with OC occur due to chemoresistance, mechanisms aiding in reversing resistance or preventing its occurrence should be investigated. Several studies have proven the involvement of hTERT in cancer cell immortalization. Moreover, Ca-125 affects the response of cancer cells to chemotherapy and glucose restriction decreases cancer cell proliferation and viability (34). Based on these facts, the effect of chemotherapy combined with glucose restriction on the expression and activity of Ca-125 and telomerase was assessed in the present study. Additionally, the modulation of $\mathrm{Ca}-125$ expression by hTERT and the possible involvement of the PI3K/Akt/mTOR signaling pathway were investigated.

\section{Materials and methods}

Cell culture and drugs. The present study was performed on 3 OC cell lines, namely the Igrov-1 (Institut Gustave Roussy), SKOV-3 and Ovcar-3 (both American Type Culture Collection) cell lines. SKOV-3 and Igrov-1 cells were cultured in $4.5 \mathrm{~g} / 1 \mathrm{DMEM}$ supplemented with $10 \% \mathrm{FBS}$ and $1 \%$ penicillin-streptomycin (PS; Sigma-Aldrich; Merck KGaA) according to the manufacturer's protocol, whereas Ovcar-3 cells was cultured in F12 medium supplemented with $20 \%$ FBS and 1\% PS (Sigma-Aldrich; Merck KGaA). All cells were incubated in a humidified incubator at $37^{\circ} \mathrm{C}$ with $5 \% \mathrm{CO}_{2}$. CDDP (Sigma-Aldrich; Merck KGaA) was freshly dissolved in $0.9 \% \mathrm{NaCl}$ solution, whereas PTX (Sigma-Aldrich; Merck $\mathrm{KGaA}$ ) was prepared in DMSO and stored at $-20^{\circ} \mathrm{C}$.

Short-term combinatorial treatment. The three OC cell types were seeded in 6 -well plates $\left(2 \times 10^{5}\right.$ cells/well $)$ and treated with $20 \mu \mathrm{M}$ cisplatin (CDDP) and $100 \mathrm{nM}$ paclitaxel (PTX) for $48 \mathrm{~h}$ at $37^{\circ} \mathrm{C}$ at $80 \%$ confluence. This treatment was performed in three different cell culture media: i) DMEM with $4.5 \mathrm{~g} / 1$ glucose, ii) DMEM with $1 \mathrm{~g} / 1$ glucose and iii) DMEM with $0.5 \mathrm{~g} / 1$ glucose. The negative control corresponded to non-treated cells. The supernatant was subsequently collected and the treated cells were subjected to RNA extraction using Nucleospin RNA Extraction kit (Macherey-Nagel, GmbH).

Generation of platinum-taxane escape (PTES) cells (35). To generate PTES cells, $1 \times 10^{5}$ SKOV-3, Ovcar-3 and Igrov-1 cells were seeded in 6 -well plates and treated at $37^{\circ} \mathrm{C}$ with $20 \mu \mathrm{M}$ CDDP for $1 \mathrm{~h}$, followed by $100 \mathrm{nM}$ PTX for $3 \mathrm{~h}$ once per week 
for 6 weeks. Prior to and during the treatment, the cells were exposed to glucose restriction for $48 \mathrm{~h}$ by administering three different glucose concentrations $(4.5,1$ and $0.5 \mathrm{~g} / 1$ glucose) in the culture media. After 6 weeks, the live cells were considered as PTES cells.

Determination of telomere length. The PTES cells remained in culture for 1 month after the treatment, and were subsequently harvested and subjected to DNA extraction using the Nucleospin DNA Extraction kit (Macherey-Nagel, GmbH) following the manufacturer's protocol. Telomere length was assessed according to the protocol proposed by R. Cawthon (36) Briefly, quantitative PCR (qPCR) was performed using the following primer pairs: Telo forward, 5'-CGGTTTGTTTGG GTTTGGGTTTGGGTTTGGGTTTGGGTT-3' and reverse, 5'-GGCTTGCCTTACCCTTACCCTTACCCTTACCCTTAC CCT-3'); and 36B4 (reference gene), forward, 5'-CAGCAA GTGGGAAGGTGTAATCC-3' and reverse, 5'-CCCATTCTA TCAACGGGTACAA-3'. The following thermocycling conditions were applied: For telomeres, $5 \mathrm{~min}$ at $95^{\circ} \mathrm{C}$, followed by 18 cycles of $95^{\circ} \mathrm{C}$ for $15 \mathrm{sec}, 54^{\circ} \mathrm{C}$ for $2 \mathrm{~min}$ and $72^{\circ} \mathrm{C}$ for $10 \mathrm{sec}$, and then $40^{\circ} \mathrm{C}$ for $30 \mathrm{sec}$; and for $36 \mathrm{~b} 4,10 \mathrm{~min}$ at $95^{\circ} \mathrm{C}$, followed by 30 cycles of $95^{\circ} \mathrm{C}$ for $15 \mathrm{sec}, 58^{\circ} \mathrm{C}$ for $60 \mathrm{sec}$ and $72^{\circ} \mathrm{C}$ for $10 \mathrm{sec}$, and then $40^{\circ} \mathrm{C}$ for $30 \mathrm{sec}(37)$.

Treatment with hTERT and PI3K/Akt/mTOR inhibitors. A total of $1 \times 10^{5}$ SKOV-3, Ovcar-3 and Igrov-1 cells were seeded in 6 -well plates. Once they reached $80 \%$ confluence, these cells were treated at $37^{\circ} \mathrm{C}$ for $48 \mathrm{~h}$ with the following inhibitors: Telomerase inhibitors BIBR-1532 (5 and $10 \mu \mathrm{M})$, costunolide (5 and $10 \mu \mathrm{M}$ ) and MST-312 (1 and $2 \mu \mathrm{M})$; PI3K inhibitors PI 828, wortmanin and GSK $(10 \mu \mathrm{M})$; AKT inhibitor GSK 690693 (100 nM); and mTOR inhibitor rapamycin (200 nM) (all Tocris Bioscience). The negative control corresponded to non-treated cells maintained in the same conditions as treated cells. In order to indicate the concentrations that should be used for each inhibitor, a toxicity test was performed, and the concentrations were chosen according to the highest concentration that has no toxic effect, therefore no effect on cell viability.

hTERT silencing. Small interfering RNA (siRNA, $5 \mathrm{nmol}$ ) specific for hTERT (sense, 5'-GGAGCAAGUUGCAAAGCA UTT-3' and antisense, 5'-AUGCUUUGCAACUUGCUC CAG-3') with non-silencing (negative control) and cell death (positive control) siRNAs were used for hTERT silencing (all Qiagen Inc.). The SKOV-3, Ovcar-3 and Igrov-1 cells were seeded in 6-well plates at a density of $2 \times 10^{5}$ cells/well and transfected for $72 \mathrm{~h}$ with the siRNAs at a concentration of $20 \mu \mathrm{M}$ using the HighPerfect transfection reagent (Qiagen, Inc.), according to the manufacturer's protocols. Knockdown efficacy of hTERT was confirmed by reverse transcription-quantitative polymerase chain reaction (RT-qPCR).

Transfection with hTERT-wild type construct. The three cell lines were transfected with two types of vectors, pBabe-neo-hTERT (cat. no. 1774) and pBabe-neo (control; cat. no. 1767), gifted from Addgene, Inc. After plasmid purification from transformed bacteria using a GenElute HP Plasmid Maxiprep kit (Sigma-Aldrich; Merck KGaA), the transfection was performed using Attractene Transfection Reagent (Qiagen Inc.), according to the manufacturer's protocols. Briefly, the cells were seeded in 6-well plates at a density of $0.5 \times 10^{6}$ cells/well. Prior to seeding, $1.2 \mu \mathrm{g}$ of plasmid, attractene and serum-free DMEM (4.5 g/l glucose; for SKOV-3 and Igrov-1), or F-12 for Ovcar-3, were mixed in the wells and incubated for $15 \mathrm{~min}$ at room temperature. Subsequently, cells were seeded in 6-well plates for $48 \mathrm{~h}$ at $37^{\circ} \mathrm{C}$ prior to subsequent experiments.

$R T-q P C R$. To assess the effect of CDDP + PTX treatment on the mRNA expression of hTERT, Ca-125 and certain molecules [interleukin (IL)-6, IL-8, bone morphogenetic protein 2 (BMP2) and excision repair cross-complementation group 1 (ERCC1)] involved in chemoresistance, total RNA was extracted from the PTES and 48-h treated cells using Nucleospin RNA extraction kit. In addition, cells treated with hTERT and PI3K/Akt/mTOR inhibitors underwent RNA extraction using Nucleospin RNA extraction kit. Total RNA (40 ng) was reverse transcribed into cDNA using the iScript cDNA synthesis kit (Bio-Rad Laboratories, Inc.) according to the manufacturer's instruction. Subsequently, the mRNA expression levels of hTERT, Ca-125, IL-6, IL-8, BMP2 and ERCC1, glucose transporters 1 and 3 (GLUT-1 and GLUT-3) and hypoxia inducible subunit $\alpha(\mathrm{HIF} 1 \alpha)$, and the internal reference gene GAPDH were quantified by qPCR using the QuantiFast SYBR Green PCR kit (Qiagen, Inc.) using specific primers for each gene (Table I). cDNA amplification was performed following a PCR program of 40 cycles, with denaturation at $95^{\circ} \mathrm{C}$ for $10 \mathrm{sec}$ and annealing at $58^{\circ} \mathrm{C}$ (IL-6, IL-8, BMP-2 and Ca-125) or $60^{\circ} \mathrm{C}$ for $30 \mathrm{sec}$, followed by elongation at $72^{\circ} \mathrm{C}$ for $10 \mathrm{sec}$ (hTERT, ERCC1 and GAPDH) using a Rotor-Gene qPCR cycler (Qiagen $\mathrm{GmbH}$ ). The mRNA levels were quantified using the $2^{-\Delta \Delta \mathrm{Cq}}$ method, where the control was normalized to 1 and the treated samples were compared with their control (38).

Measurement of Ca-125 in cell supernatant. Ca-125 levels secreted into the supernatant by treated and control SKOV-3, Ovcar-3 and Igrov- 1 cells $\left(5 \times 10^{5}\right.$ cells) were quantified using the DuoSet Human Ca-125/MUC16 ELISA Kit (R\&D Systems, Inc; cat. no. DY990) according to the manufacturer's protocols. The supernatant was collected after all treatments were performed and then assayed. The optical density, which is proportional to $\mathrm{Ca}-125$ concentration, was measured using an ELISA reader (Thermo Fisher Scientific, Inc.) at $450 \mathrm{~nm}$ and the results were normalized according to the number of cells.

Statistical analysis. All data are presented as the mean \pm SD and each experiment was repeated at least three times. All data were assessed with SPSS software using one-way ANOVA followed by the LSD post hoc test. $\mathrm{P}<0.05$ was considered to indicate a statistically significant difference.

\section{Results}

Short-term combination of chemotherapy and glucose restriction. To study the effect of glucose restriction on the efficacy of chemotherapy, a 48-h short-term treatment was performed on the SKOV-3, Ovcar-3 and Igrov-1 cell lines using three 
Table I. List of primer sequences.

\begin{tabular}{|c|c|}
\hline Gene & Primer sequence $\left(5^{\prime}-3^{\prime}\right)$ \\
\hline \multirow[t]{2}{*}{ hTERT } & F: CGGAAGAGTGTCTGGAGCAA \\
\hline & R: CTCCCACGACGTAGTCCATG \\
\hline \multirow[t]{4}{*}{$\mathrm{Ca}-125$} & F: CTGCATGTACTCCCATCTCTTCAA \\
\hline & GAGAGAGATGGGAGTAGATGCAG \\
\hline & R: CTGCATCTACTCCCATCTCTCTC \\
\hline & TTGAAGAGATGGGAGTAGATGCAG \\
\hline \multirow[t]{2}{*}{ IL-6 } & F: TCAATATTAGAGTCTCAACCCCCA \\
\hline & R: TTCTCTTTCGTTCCCGGTGG \\
\hline \multirow[t]{2}{*}{ IL-8 } & F: CCACCGGAGCACTCCATAAG \\
\hline & R: GATGGTTCCTTCCGGTGGTT \\
\hline \multirow[t]{2}{*}{ BMP2 } & F: TTTCAATGGACGTGTCCCCG \\
\hline & R: AGCAGCAACGCTAGAAGAA \\
\hline \multirow[t]{2}{*}{ ERCC1 } & F: AGGCACAAGTAACAGGCTCAC \\
\hline & R: AAGGTCGTAATTCCTTTGCAC \\
\hline \multirow[t]{2}{*}{ GAPDH } & F: TGAGCCAGATAGGCTGGAA \\
\hline & R: TAACGCAGGCGATGTTGTC \\
\hline \multirow[t]{2}{*}{ GLUT-3 } & F: CCCAGATCTTTGGTCTGGAA \\
\hline & R: AAGGGCTGCACTTTGTAGGA \\
\hline \multirow[t]{2}{*}{ GLUT-1 } & F: GATGATGCGGGAGAAGAAGG \\
\hline & R: AAGACAGCGTTGATGCCAGAC \\
\hline \multirow[t]{2}{*}{$\mathrm{HIF} 1 \alpha$} & F:TATGAGCCAGAAGAACTTTTAGGC \\
\hline & R: CACCTCTTTTGGCAAGCATCCTG \\
\hline
\end{tabular}

hTERT, human telomerase reverse transcriptase; Ca-125, cancer antigen 125; IL-6, interleukin-6; IL-8, interleukin-8; BMP2, bone morphogenetic protein 2; ERCC1, excision repair cross-complementation group 1; GLUT-3, glucose transporter 3; GLUT-1, glucose transporter 1 ; HIF1 $\alpha$, hypoxia inducible factor subunit $\alpha$; F, forward; $\mathrm{R}$, reverse.

different glucose concentrations. The comparison between the control and treated cells in the same glucose conditions revealed an increase in the mRNA expression of hTERT in the treated cells (range, 1.5-2.5 fold; Fig. 1A). Moreover, this short-term treatment also lead to an increase in Ca-125 mRNA levels (range, 1.5-3 fold; Fig. 1B). As presented in Fig. 1C, an approximate 2-fold increase was observed in the secretion of Ca-125 in the Ovcar-3 cells; however, Ca-125 secretion by the SKOV-3 and Igrov-1 cells was undetectable by ELISA. Nevertheless, no significant difference was observed among the cells treated in different glucose conditions, indicating that the expression of both proteins was not affected by the decrease in glucose levels during the treatment.

Generation of PTES cells. For the development of OC cell lines with double resistance to cisplatin and paclitaxel, the SKOV-3, Ovcar-3 and Igrov-1 cell lines were treated with CDDP and PTX once per week for 6 consecutive weeks. The doses of the chemotherapeutic agents (20 $\mu \mathrm{M}$ CDDP and $100 \mathrm{nM}$ PTX) were chosen according to the peak plasma levels reached when $100 \mathrm{mg} / \mathrm{m}^{2}$ of CDDP and $175 \mathrm{mg} / \mathrm{m}^{2}$ of PTX were administered intravenously in patients with ovarian cancer (35). The cells were treated with CDDP for $1 \mathrm{~h}$ and PTX for $3 \mathrm{~h}$.
The treatment durations correspond to the half-life of these chemotherapeutic agents in the human body (35). The treatment was performed in culture media of the three cell lines with the following glucose concentrations, which correspond to the physiological alterations observed in blood glucose levels: i) $4.5 \mathrm{~g} / 1$ glucose, high; ii) $1 \mathrm{~g} / 1$ glucose, low; and (iii) $0.5 \mathrm{~g} / 1$ glucose, fasting.

After 6 weeks of treatment, the remaining living cells were considered as PTES cells. Six PTES cell types were generated: PTES SKOV-3 cultured in three different glucose concentrations and PTES Igrov-1 cultured in these same conditions. Despite their resistance to clinically relevant concentrations of cisplatin, PTES Ovcar-3 cells could not be generated. In order to confirm the decrease in the sensitivity of PTES cells to additional chemotherapeutic challenges, these cells were subjected to a single exposure of higher doses of CDDP, PTX and a combination of both treatments in the same glucose conditions as the initial treatment. According to the obtained results, SKOV-3 and Igrov-1 PTES cells required higher concentrations of the chemotherapeutic treatment to reach the same levels of proliferation observed in the parental cells treated with lower doses (Fig. 2). The chemoresistance profile of the PTES cells was evaluated by quantifying the mRNA expression levels of the IL-6, IL-8 and BMP2 proteins, implicated in environment-mediated drug resistance, and the ERCC1 protein, which is directly involved in DNA repair (39). The obtained results revealed a significant increase in the expression of these mRNAs in all PTES cells, indicating that these cells may have developed resistance to the chemotherapeutic treatment (Fig. 3). Additional investigations concerning the effect of the combination of chemotherapy with induced hypo-, normo- and hyperglycemia on the expression of GLUT1, GLUT3 and HIF1 $\alpha$ were performed by measuring the mRNA expression levels of these genes in control and PTES cells. The results revealed a significant increase in the expression of both glucose transporters in PTES cells treated with the three glucose concentrations, with no significant difference between them (Fig. 4A and B). However, HIF1 $\alpha$ expression level was significantly increased only in SKOV-3 4.5 PTES cells (Fig. 4C).

Decrease of telomere length and hTERT and Ca-125 expression in PTES cells. Next, the effect of this combined long-term (6 weeks) treatment on the expression of hTERT, the catalytic subunit of telomerase, was assessed in all PTES cell lines. The results demonstrated a $20 \%$ decrease in the hTERT mRNA expression levels of PTES SKOV-3 cells treated with $4.5 \mathrm{~g} / 1$ of glucose; however, this decrease reached $40 \%$ with $0.5 \mathrm{~g} / 1$ of glucose. A similar effect was observed in the PTES Igrov-1 cells, where the reduction ranged from $15 \%$ with $4.5 \mathrm{~g} / 1$ glucose to $60 \%$ with fasting glucose concentrations (Fig. 5A). Telomere length was subsequently evaluated to assess the effect of this reduction on telomerase expression. A non-significant decrease was observed in PTES SKOV-3 and Igrov-1 cultured with 4.5 and $1 \mathrm{~g} / 1$ glucose. However, the decrease in telomere length was greater in the both PTES cell lines treated with fasting glucose concentrations (Fig. 5B). Additionally, the Ca-125 mRNA expression levels were quantified in chemosensitive and chemoresistant cells. It was observed that Ca-125 expression decreased in a similar manner as the hTERT 

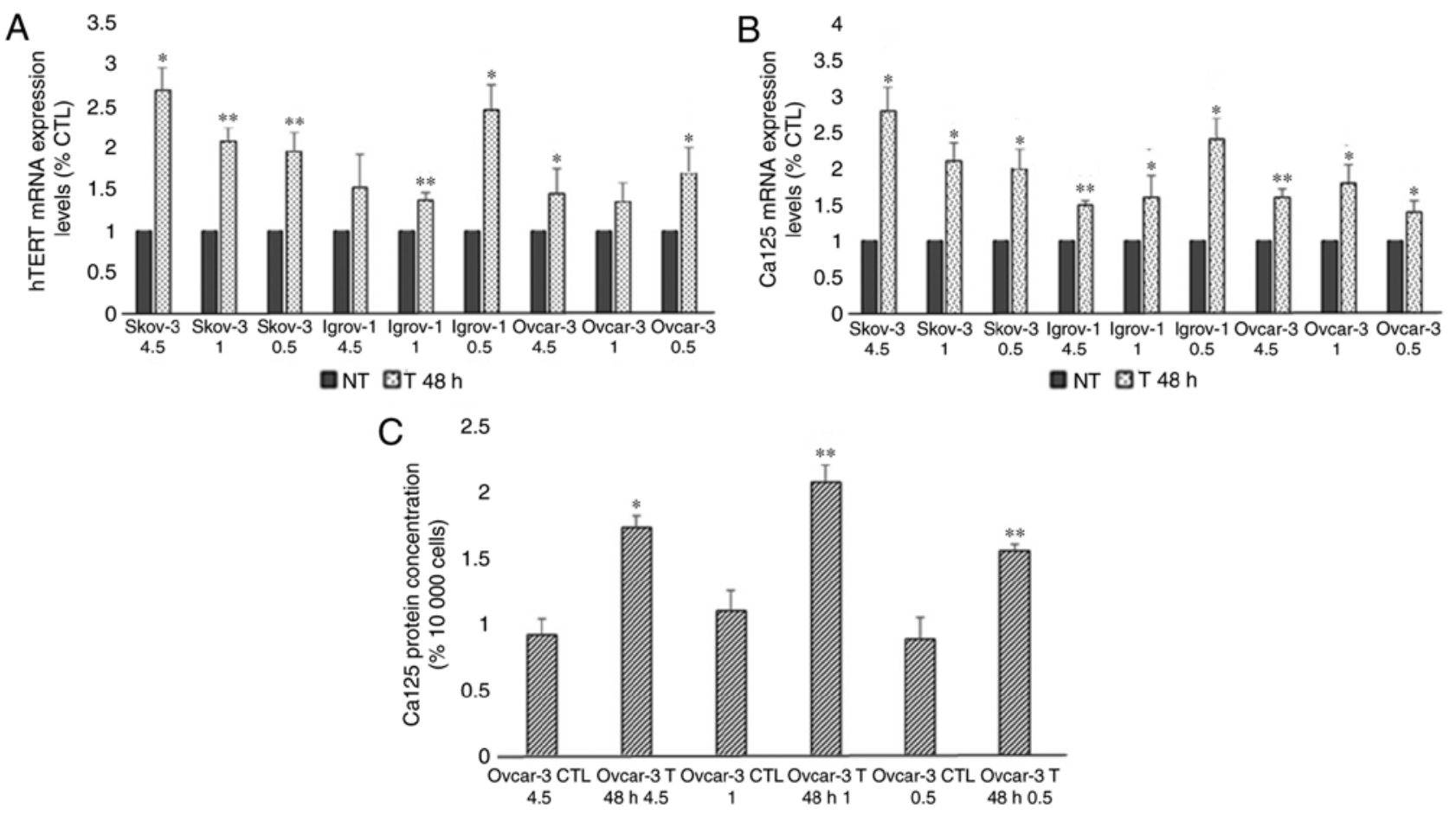

Figure 1. Effect of 48-h combinatory treatment of CDDP, PTX and glucose restriction on hTERT and Ca-125 expression and secretion. SKOV-3, Ovcar-3 and Igrov-1 cells were seeded in 6 well-plates. These cells were treated with three different glucose concentrations $(4.5,1$ and $0.5 \mathrm{~g} / 1)$ with $20 \mu \mathrm{M} \mathrm{CDDP}$ and $100 \mathrm{nM}$ PTX for $48 \mathrm{~h}$. Supernatant was collected following the treatment in order to quantify secreted Ca-125 using ELISA. The cells were then harvested, and RNA was isolated for hTERT and Ca-125 mRNA quantification by reverse transcription-quantitative polymerase chain reaction. (A and B) hTERT and Ca-125 mRNA expression levels were found to be increased in all treated cells; these results did not appear to be significantly affected by the different glucose levels. (C) A similar effect was observed with regard to Ca-125 secretion in the treated Ovcar-3 cells. The values displayed in this figure refer to values adjusted to 10,000 cells, since cell number usually affects the levels of secreted proteins. Cell count was performed following cell harvesting and values were normalized to 10,000 cells. Each value represents the mean from three different experiments. The control group was set to 1, and the remaining values were compared with the control. The results are presented as the mean $\pm \mathrm{SD}$. " $\mathrm{P}<0.05$ vs. control group, and ${ }^{* *} \mathrm{P}<0.01$ vs. control group. CTL, control; CDDP, cisplatin; PTX, paclitaxel; hTERT, human telomerase reverse transcriptase; Ca-125, cancer antigen 125; NT, non-treated cells.
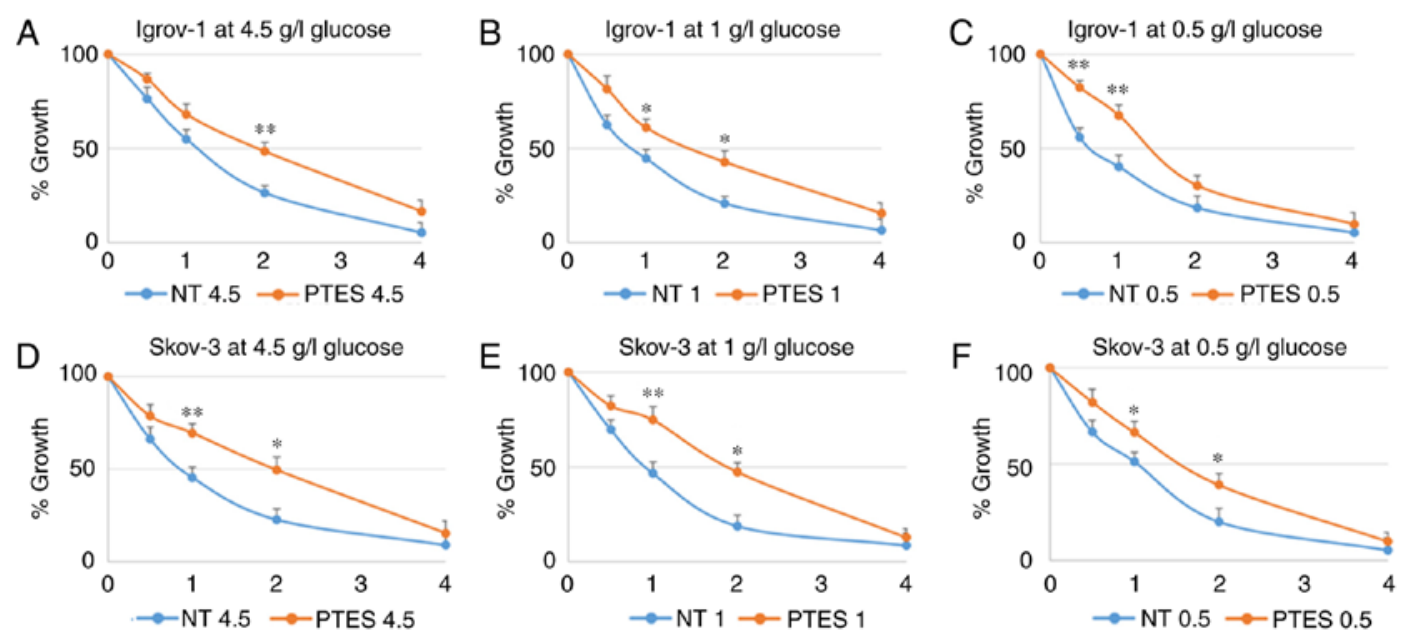

Figure 2. Characterization of SKOV-3 and Igrov-1 cells with induced resistance to CDDP and PTX. Igrov-1 (A-C) and SKOV-3 (D-F) control and PTES cells were treated with a single exposure of increasing doses of CDDP + PTX. The numbers presented on the X-axis $(1,2,3$ and 4$)$ correspond to CDP1, CDP2, CDP3 and CDP4, respectively. CDP 1 indicates the treatment of PTES cells with one single physiological dose of the chemotherapeutic agents (20 $\mu$ M CDDP for $1 \mathrm{~h}+100 \mathrm{nM}$ PTX for $3 \mathrm{~h}$ ). CDP 2 indicates the treatment of PTES cells with twice the physiological dose, CDP 3 with triple the dose, and CDP 4 with four times the physiological dose. The control group value was set to 1 and the remaining values were compared with the control. The results are presented as the mean $\pm \mathrm{SD}$. ${ }^{*} \mathrm{P}<0.05$ compared with the control group and ${ }^{* *} \mathrm{P}<0.01$ compared with the control group. CDDP, cisplatin; PTX, paclitaxel; PTES, platinum-taxane escape; NT, non-treated cells.

expression; however, the reduction ranged between 60 and $80 \%$ in the PTES SKOV-3 cells and between 65 and $85 \%$ in the PTES Igrov-1 cells (Fig. 5C).
Effect of hTERT inhibition on Ca-125 expression and secretion. Based on the aforementioned results, a parallel change in the expression of hTERT and Ca-125 was observed after both 

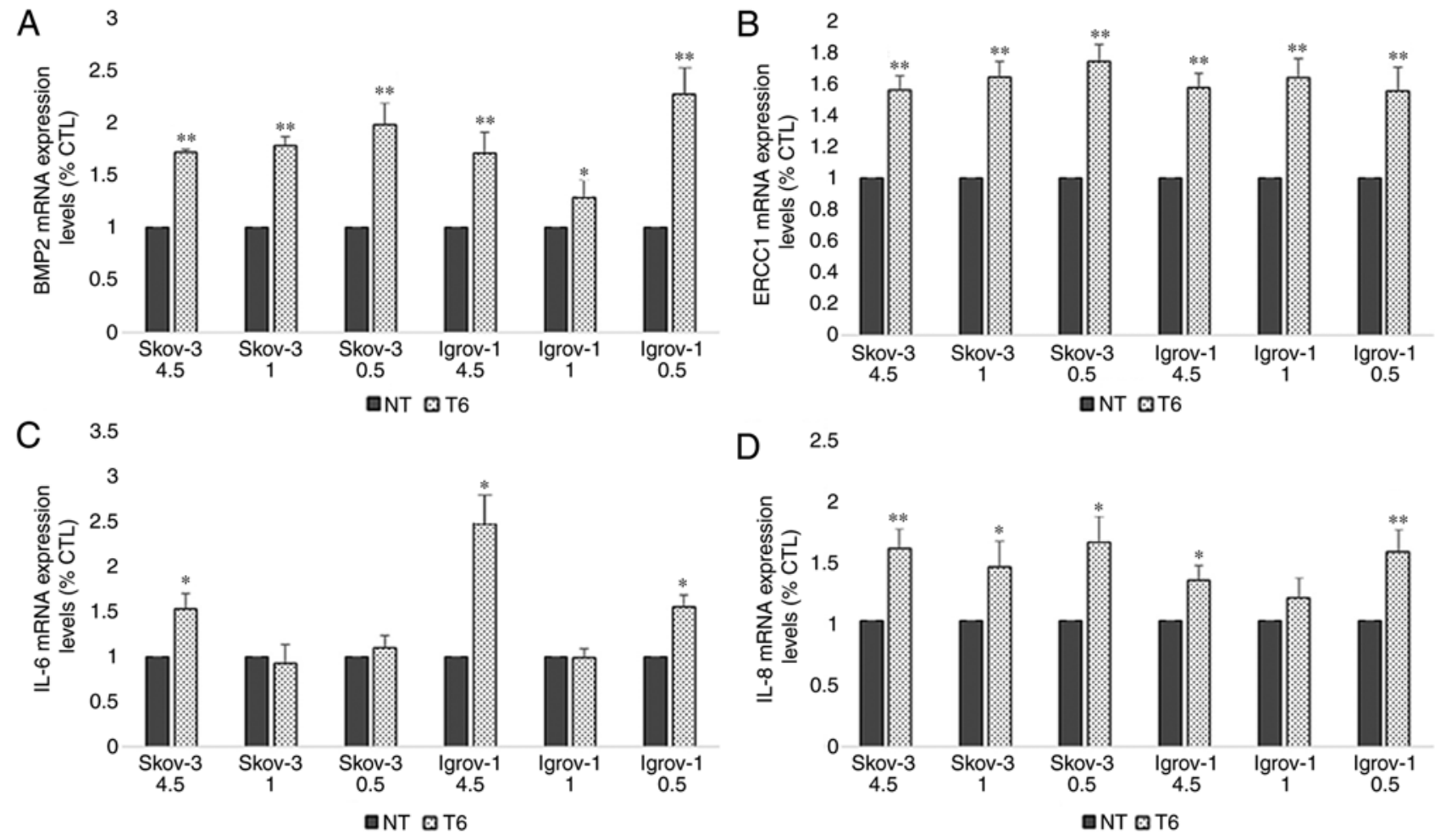

D $\quad 2.5$

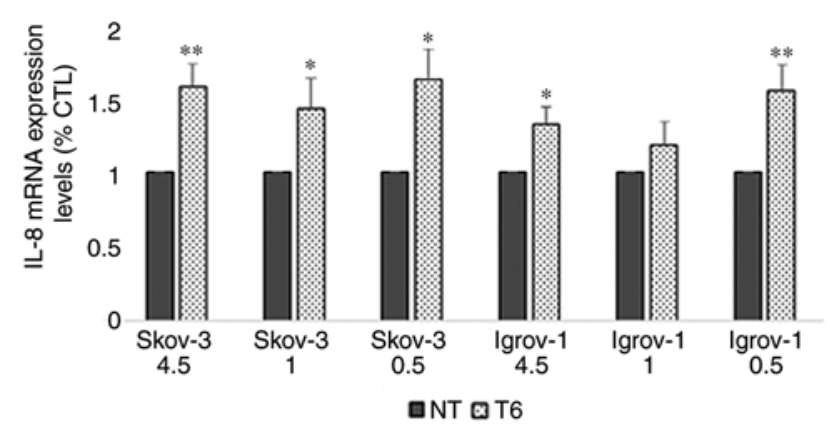

Figure 3. Effect of 6-week treatment on markers of chemoresistance in PTES cells. Cells from the three ovarian cancer cell lines were seeded in 6-well plates. These cells were cultured with $4.5,1$ and $0.5 \mathrm{~g} / 1$ glucose concentrations $48 \mathrm{~h}$ prior to the treatment. Next, they were treated with $20 \mu \mathrm{M} \mathrm{CDDP}$ for $1 \mathrm{~h}$, followed by $100 \mathrm{nM}$ PTX for $3 \mathrm{~h}$. This procedure was repeated once per week for six consecutive weeks. Subsequently, the cells were harvested and subjected to RNA extraction, followed by reverse transcription-quantitative polymerase chain reaction for (A) BMP2, (B) ERCC1, (C) IL-6 and (D) IL-8. A significant increase was observed in the expression of the majority of these proteins under the different conditions. The observed values represent the mean from three different experiments. Using the $2^{-\Delta \Delta C q}$ method, the control group was set to 1 , and the remaining results were compared with the control. The results are presented as the mean $\pm \mathrm{SD}$. ${ }^{*} \mathrm{P}<0.05$ vs. control group, and ${ }^{* * *} \mathrm{P}<0.01$ vs. control group. PTES, platinum-taxane escape; CDDP, cisplatin; PTX, paclitaxel; BMP2, bone morphogenetic protein 2; IL-6, interleukin-6; IL-8, interleukin-8; ERCC1, excision repair cross-complementation group 1.
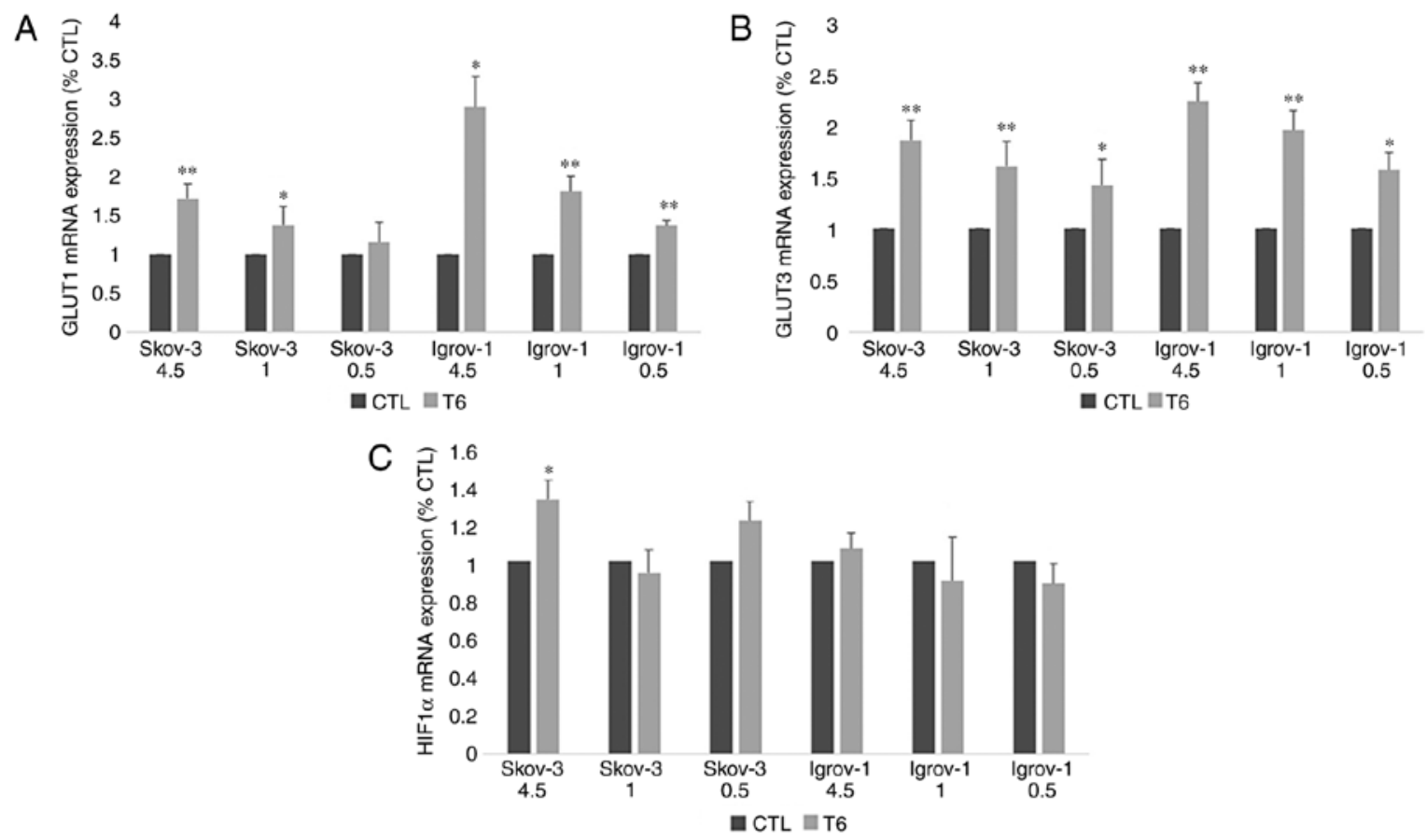

Figure 4. Effect of 6-week treatment in hyper-, normo- and hypoglycemic conditions on glucose transporters and HIF1 $\alpha$ expression in PTES cells. Control and PTES cells were harvested and subjected to RNA extraction, followed by reverse transcription-quantitative polymerase chain reaction for GLUT1 (A), GLUT3 (B) and HIF1 $\alpha$ (C). A significant increase was observed in the expression of the glucose transporters under the different conditions. The observed values represent the mean from three different experiments. Using the $2^{-\Delta \Delta C q}$ method, the control group was set to 1 , and the remaining results were compared with the control. The results are presented as the mean $\pm \mathrm{SD}$. ${ }^{*} \mathrm{P}<0.05$ vs. control group, and ${ }^{* *} \mathrm{P}<0.01$ vs. control group. CTL, control; HIFl $\alpha$, hypoxia inducible factor 1 subunit $\alpha$; PTES, platinum-taxane escape; GLUT1, glucose transporter 1; GLUT3, glucose transporter 3. 

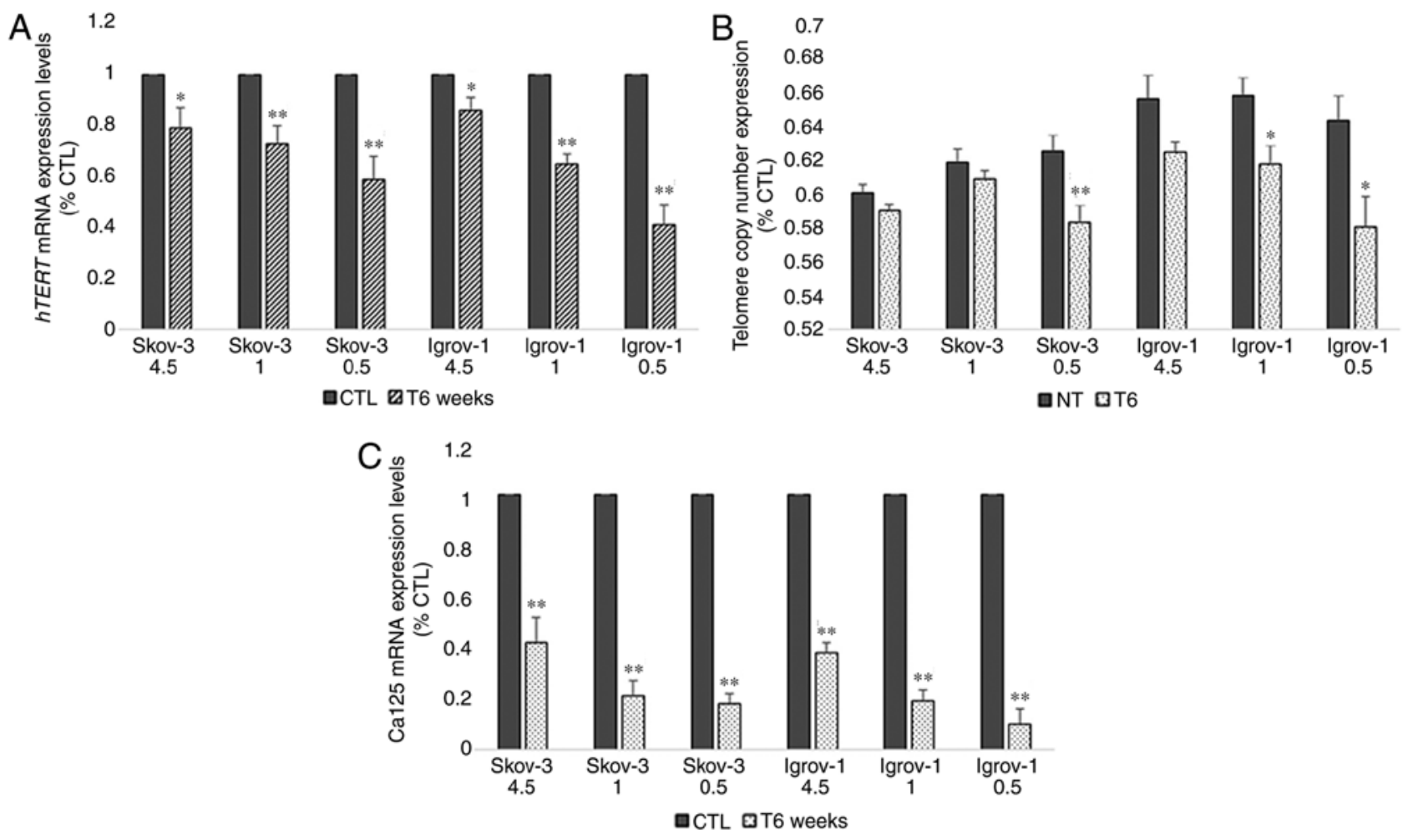

Figure 5. hTERT and Ca-125 mRNA expression and telomere length in PTES cells. Cells from the 6 PTES cell lines and their corresponding controls were harvested, subjected to RNA extraction to quantify hTERT and Ca-125 mRNA expression by reverse transcription-quantitative polymerase chain reaction and subjected to DNA extraction for telomere length quantification by the telomere length assay following Cawthon method. (A and C) A significant decrease was observed in the mRNA expression of both hTERT and Ca-125; the lowest levels were observed in cells treated with $0.5 \mathrm{~g} / \mathrm{l}$ glucose. (B) The decrease in telomere length was observed in all PTES cells; however, a significant decrease was demonstrated only in cells treated with fasting glucose concentrations. The values observed represent the mean of three different experiments. The results are presented as the mean $\pm \mathrm{SD}$. ${ }^{*} \mathrm{P}<0.05$ vs. control group, and ${ }^{* *} \mathrm{P}<0.01 \mathrm{vs}$. control group. CTL, control; hTERT, human telomerase reverse transcriptase; PTES, platinum-taxane escape; Ca-125, cancer antigen 125.

short-term and long-term treatments. Taking into consideration that telomerase regulates the expression of various genes, the role of hTERT in the modulation of $\mathrm{Ca}-125$ expression and secretion was investigated. Thus, chemosensitive cells from the three cell lines were treated with three telomerase inhibitors: BIBR1532 at 5 and $10 \mu \mathrm{M}$, costunolide at 5 and $10 \mu \mathrm{M}$ and MST-312 at 1 and $2 \mu \mathrm{M}$. The concentrations of these inhibitors were selected according to a dose-response curve, which demonstrated that they did not exert any cytotoxic effects. The results indicated a significant decrease in the mRNA and protein expression of Ca-125 in the three cell lines after treatment with all three inhibitors compared with the control. However, the highest effect was observed with BIBR1532 at $5 \mu \mathrm{M}$ for SKOV-3 and Ovcar-3 and at $10 \mu \mathrm{M}$ for Igrov-1 (Fig. 6A and B). Transfection of all three cell lines with hTERT siRNA was performed to confirm the direct involvement of hTERT in Ca-125 modulation and to exclude the possibility of extratelomeric action of the hTERT inhibitors. In order to make sure that the transfection was successful, hTERT mRNA expression was assessed in control and transfected cells. The results (Fig. 7A) demonstrated a significant decrease $(\sim 90 \%)$ in hTERT expression level in transfected cells compared with control cells. As expected, the mRNA expression pattern obtained by gene silencing was similar to that obtained after treatment with the inhibitors (Fig. 6C and D). A significant decrease was observed in the mRNA expression of $\mathrm{Ca}-125$ in the three cell lines, and in the protein expression of $\mathrm{Ca}-125$ in Ovcar-3 cell line following hTERT silencing.
Effect of hTERT overexpression on Ca-125 expression and secretion. After investigating the effect of hTERT inhibition, the SKOV-3, Ovcar-3 and Igrov-1 cells were transfected with pBabe-neo-hTERT to evaluate the effect of telomerase overexpression on Ca-125 expression and secretion. In order to make sure that the transfection was successful, hTERT mRNA expression was assessed in control and transfected cells. The results (Fig. 7B) demonstrated a significant 25-30 fold increase in hTERT expression level in transfected cells compared with control cells. The results indicated a significant increase affecting both the mRNA and protein levels of $\mathrm{Ca}-125$ after $48 \mathrm{~h}$ of transfection. Notably, an increase of $\sim 30 \%$ in the SKOV-3 and Ovcar-3 cells, and an increase of 50\% in Igrov-1 cells was observed with regards to Ca-125 mRNA expression, compared with the control (Fig. 6E and F).

Effect of PI3K/Akt/mTOR signaling pathway inhibition on Ca-125 expression and secretion. As aforementioned, previous studies have investigated the potential link between Ca-125 and the protein mTOR. Since this protein is implicated in the $\mathrm{PI} 3 \mathrm{~K} / \mathrm{Akt} / \mathrm{mTOR}$ signaling pathway and a mutual modulation links hTERT to this pathway (40), the regulation of Ca-125 expression and secretion by PI3K/Akt/mTOR was examined. The SKOV-3, Ovcar-3 and Igrov-1 cells were treated with various inhibitors specific to proteins in this pathway for $48 \mathrm{~h}$. The decrease in Ca-125 mRNA expression reached $60 \%$ after treatment with PI3K and Akt inhibitors (PI828, GSK 2126458 

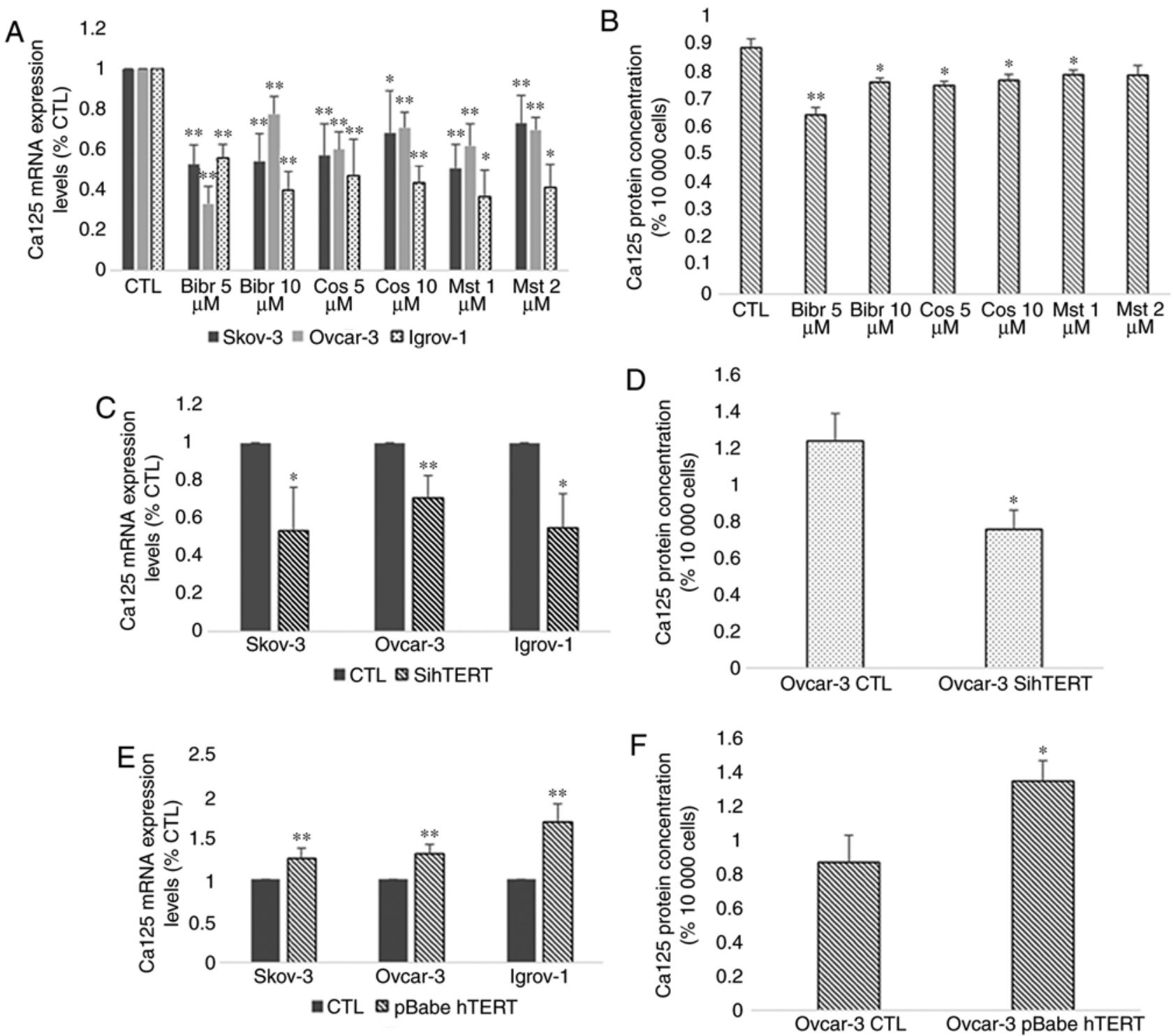

Figure 6. Effect of hTERT inhibition and overexpression on Ca-125 mRNA and protein expression. Cells from the three cell lines were cultured in 6-well plates. At $80 \%$ confluence, these cells were treated with telomerase inhibitors BIBR1532 (5 and $10 \mu \mathrm{M})$, costunolide (5 and $10 \mu \mathrm{M})$ and MST-312 (1 and $2 \mu \mathrm{M})$. Next, the supernatant was collected, and the cells were harvested for RNA extraction. Ca- $125 \mathrm{mRNA}$ expression was assayed by reverse transcription-quantitative polymerase chain reaction and protein secretion levels by ELISA. (A and B) A significant decrease was observed after treatment with all inhibitors compared with the control; however, the greatest effect was caused by BIBR1532. In addition, the cells were transfected with siRNA for hTERT and pBabe-neo-hTERT to evaluate the effect of both gene silencing and gene overexpression on Ca-125. (C and D) The effect of sihTERT was similar to the effect of hTERT inhibitors. (E and F) However, transfection with pBabe-neo-hTERT caused a significant increase in both mRNA and protein levels of Ca-125 compared with the control. The values displayed in this figure refer to values adjusted to 10,000 cells, since cell number usually affects the levels of secreted proteins. Cell count was performed following cell harvesting and values were normalized to 10,000 cells. Each experiment was performed at least three times, and the values included in these graphs represent the mean from these experiments. The results are presented as the mean $\pm \mathrm{SD}$. "P<0.05 vs. control group, and ${ }^{* *} \mathrm{P}<0.01$ vs. control group. CTL, control; hTERT, human telomerase reverse transcriptase; sihTERT, siRNA for hTERT; siRNA, small interfering RNA; Ca-125, cancer antigen 125.

and Wortmanin for PI3K, and GSK 69029 for Akt) in the Igrov-1 cells and $40 \%$ with the mTOR inhibitor rapamycin (Fig. 8A). mRNA expression and protein secretion in the treated Ovcar-3 cells exhibited similar results (Fig. 8A and B, respectively). Thus, the PI3K/Akt/mTOR signaling pathway was indicated as a potential regulator of $\mathrm{Ca}-125$ in OC cells.

Effect of the combination of telomerase and PI3K/Akt/mTOR inhibitors on Ca-125. hTERT and the PI3K/Akt/mTOR pathway are both regulators of Ca-125 in OC cells. Taking into account that telomerase is an activator of this signaling pathway, the possible regulation of Ca- 125 by hTERT via
PI3K/Akt/mTOR was investigated. The PTES cells were treated with telomerase inhibitors (BIBR-1532, Costunolide and MST-312) combined with PI3K, Akt and mTOR inhibitors for $48 \mathrm{~h}$. However, this combination did not potentiate the effects observed on Ca-125 mRNA and protein levels in all three cell lines (Fig. 9).

\section{Discussion}

Resistance to chemotherapy is a major limitation in the treatment of various types of cancer, including OC. Several mechanisms are responsible for the onset and development of 

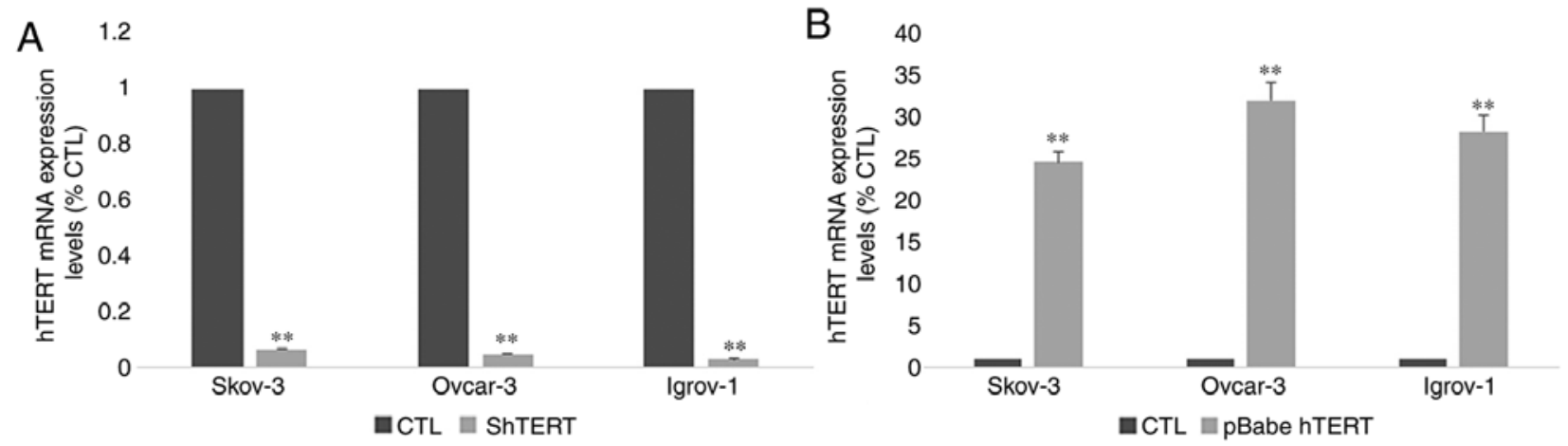

Figure 7. Effect of sihTERT and pBabe-neo-hTERT transfection on hTERT mRNA expression levels. After harvesting transfected cells, mRNA expression of hTERT was assessed using quantitative polymerase chain reaction, in order to ensure that the procedure was completed successfully. (A) The results demonstrated a significant decrease of $>90 \%$ in hTERT mRNA expression levels after silencing the expression of this gene using sihTERT. (B) On the contrary, hTERT expression levels exhibited a $\sim 25$-fold increase after transfection of the three types of ovarian cancer cells with pBabe-neo-hTERT. Each experiment was performed at least 3 times, and the values included in these graphs represent the mean from these experiments. The results are presented as the mean \pm SD. ${ }^{* *} \mathrm{P}<0.01$ vs. control group. hTERT, human telomerase reverse transcriptase; siRNA, small interfering RNA.
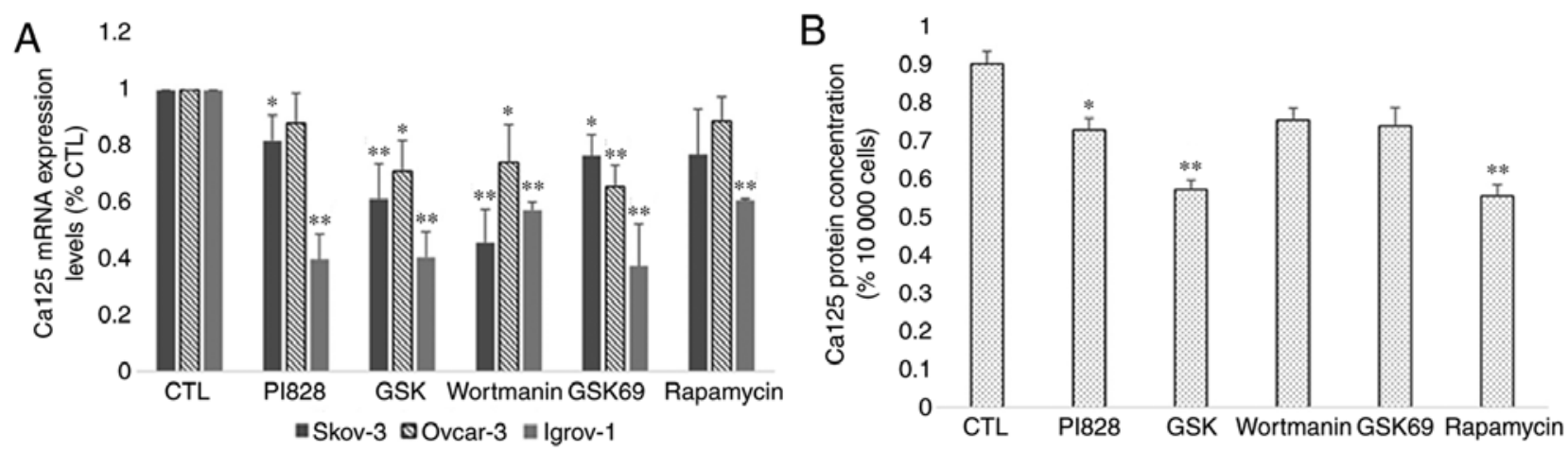

Figure 8. Effect of PI3K/Akt/mTOR inhibitors on Ca-125 mRNA and protein expression. SKOV-3, Ovcar-3 and Igrov-1 cells were seeded in 6-well plates. At $80 \%$ confluence, these cells were treated with inhibitors of PI3K (PI828, wortmanin and GSK; $10 \mu \mathrm{M}$ ), Akt (GSK690693; $100 \mathrm{nM}$ ) and mTOR (rapamycin; $200 \mathrm{nM}$ ) for $48 \mathrm{~h}$. Next, the supernatant was collected for quantification of secreted Ca-125 by ELISA, and the cells were harvested for RNA extraction, followed by reverse transcription-quantitative polymerase chain reaction for quantifying Ca-125 mRNA expression. (A) A significant decrease was observed in the majority of cells treated with the inhibitors; however, Igrov-1 exhibited the lowest values. (B) This decrease was also observed in protein secretion in the treated Ovcar-3 cells. Ca-125 level in the supernatants of SKOV-3 and Igrov-1 cell lines were undetectable using ELISA. The values displayed in this figure refer to values adjusted to 10,000 cells, since cell number usually affects the levels of secreted proteins. Cell count was performed following cell harvesting and values were normalized to 10,000 cells. Each experiment was performed at least 3 times, and the values listed in these graphs represent the mean from these experiments. The results are presented as the mean $\pm \mathrm{SD}$. ${ }^{*} \mathrm{P}<0.05$ vs. control group, and ${ }^{* *} \mathrm{P}<0.01$ vs. control group. Ca- 125 , cancer antigen 125 .

chemoresistance, including the activation of DNA repair mechanisms (41), the development of sequential genetic alterations inducing transient environment-mediated drug resistance (42) and the presence of cancer-initiating cells embedded within the tumor (43). To overcome chemoresistance, a previous study focused on the development of new strategies and treatment combinations, including the establishment of second-line chemotherapy or coupling standard treatment regimens with immunotherapy (44). Another recently explored strategy is based on the targeting of cancer cell metabolism to improve its response to therapeutics. A previous study demonstrated the effect of targeting certain glycolytic enzymes to overcome resistance to trastuzumab in breast cancer cells (45). Furthermore, a previous study on breast cancer highlighted the potential use of lactate dehydrogenase $\mathrm{A}$ as a target to reverse resistance to PTX (46). Thus, glucose availability and metabolism in cancer serve important roles in the sensitivity of cells to chemotherapeutic drugs. Based on these facts, the effect of chemotherapy combined with glucose restriction on the development of chemoresistance was evaluated in the present study. Moreover, the outcome of this combinatorial treatment on the immortality of cancer cells was investigated by studying telomerase expression and activity, and the ability of these cells to secrete the serum marker Ca-125. The PTES cells were initially treated with the chemotherapeutic agents CDDP and PTX for $48 \mathrm{~h}$ in 3 different glucose concentrations. The three concentrations were chosen so as to mimic the physiology of a patient following high, low and fasting glucose diets. Following this short-term treatment, expression of both hTERT and Ca-125 increased significantly. A similar effect on hTERT expression was observed in a previous study after treatment of hepatocellular carcinoma cells with low doses of cisplatin for $24 \mathrm{~h}$. It was reported that increased expression of the transcription factor c-MYC resulted in hTERT upregulation (47). In addition, higher Ca-125 levels after short-term treatment may be explained by the implication of this protein in the modulation of the response of OC cells to genotoxic drugs, including cisplatin (48). However, no significant 

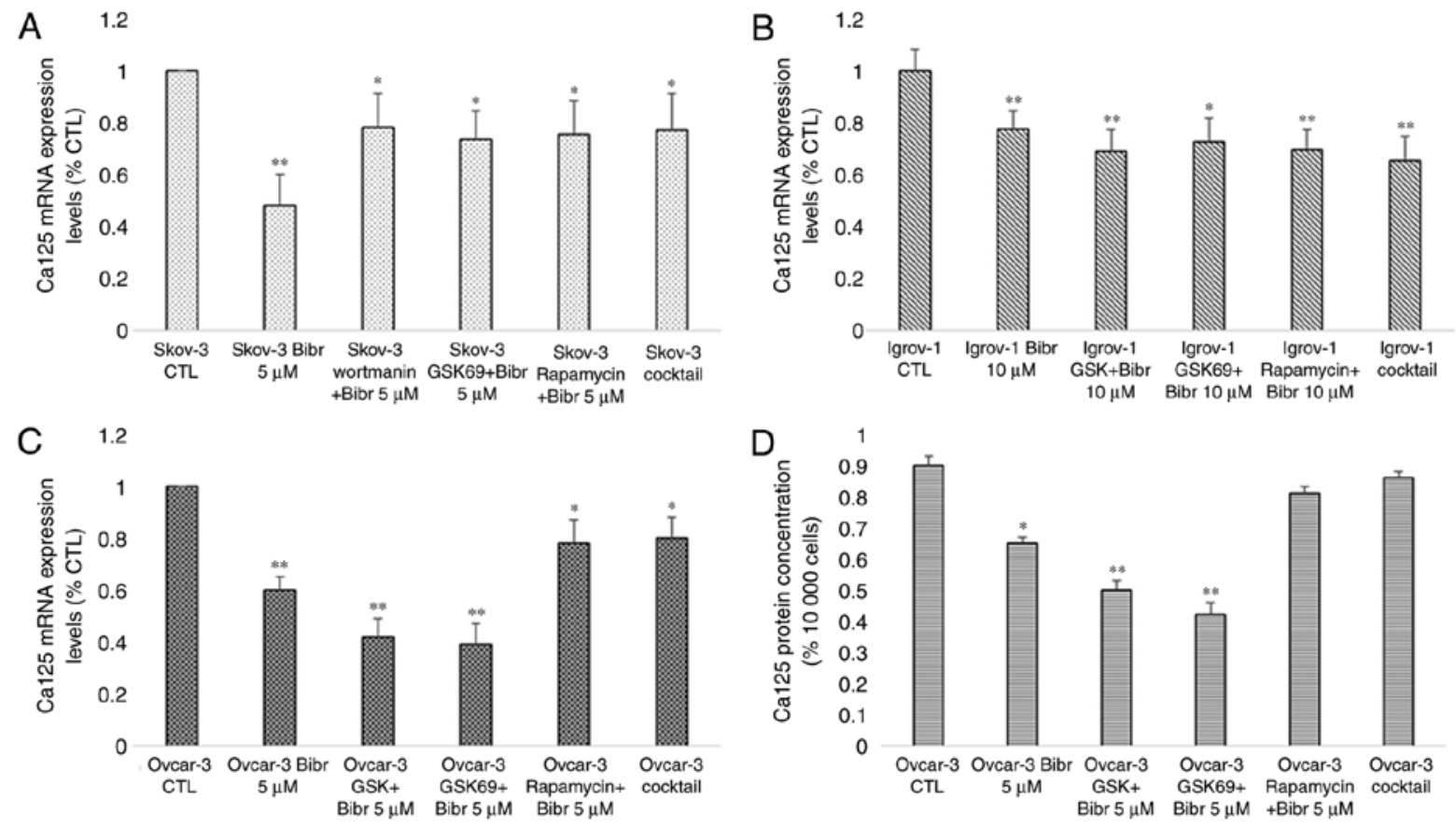

Figure 9. Effect of hTERT and PI3K/Akt/mTOR simultaneous inhibition on Ca-125 expression and secretion. Cells were seeded in 6-well plates and treated at $80 \%$ confluence with a combination of hTERT and PI3K/Akt/mTOR pathway inhibitors. Inhibitors of telomerase and PI3K were chosen according to the highest effect on $\mathrm{Ca}-125$ observed in the previous experiments. RNA extraction followed by reverse transcription-quantitative polymerase chain reaction was performed for mRNA expression and ELISA for Ca-125 protein secretion. (A-C) Combination of the inhibitors did not exhibit an additive nor a synergic effect on Ca-125 mRNA expression. (D) A similar result was observed with regard to the protein secretion levels in the Ovcar-3 cells. The term 'Cocktail' refers to the combination of all inhibitors together in one treatment. The values displayed in this figure refer to values adjusted to 10,000 cells, since cell number usually affects the levels of secreted proteins. Cell count was performed following cell harvesting and values were normalized to 10,000 cells. Each experiment was performed at least 3 times, and the values listed in these graphs represent the mean from these experiments. The results are presented as the mean \pm SD. ${ }^{*} \mathrm{P}<0.05$ vs. control group, and ${ }^{* *} \mathrm{P}<0.01$ vs. control group. hTERT, human telomerase reverse transcriptase; Ca-125, cancer antigen 125.

difference was detected among the cells treated with various glucose concentrations. This may be explained by the short period of exposure to glucose restriction and cell adaptation that requires additional time for metabolic flux changes.

After the long-term treatment of cells with specific concentrations of CDDP and PTX, the expression levels of IL-6, IL-8, BMP2 and ERCC1, which are implicated in the initiation and development of resistance to chemotherapy, were evaluated. The increased expression of all these proteins observed in the PTES cells compared with the control explains the ability of these cells to survive 6 weeks of treatment. These proteins are associated with various mechanisms implicated in chemoresistance. For instance, ERCC1 is involved in the nucleotide excision repair mechanism. Interleukin expression corresponds to the environment-mediated drug resistance developed by the PTES cells (49). However, no significant difference was observed in the expression of these markers among the PTES cells treated with various glucose concentrations. Thus, decreasing glucose availability during treatment may not directly affect the ability of cancer cells to develop chemoresistance.

Following several cellular divisions, the telomeric ends of the chromosomes reach a critical length, leading to the activation of apoptosis. However, telomerase serves a key role in the elongation of these telomeres in cancer cells. To assess the effect of the combinatorial treatment on the immortalization of the PTES cells, the mRNA expression of the catalytic subunit hTERT was examined in the present study. Previous studies revealed that telomerase expression was increased in osteosarcoma cisplatin-resistant cells, thus leading to the suppression of cisplatin-induced apoptosis (50). However, hTERT expression was significantly decreased in the PTES cells in the present study. This decrease was greater in the PTES cells treated with fasting glucose concentrations. To further investigate the effect of this reduction, the length of the telomeres in control and resistant cells was assessed. A decrease in telomere length was observed; however, the shortening of telomeres was statistically significant only in the PTES cells treated with fasting glucose concentrations. The non-significant results for 4.5 and $1 \mathrm{~g} / 1$ glucose concentrations may be explained by the fact that slight decreases affecting telomerase expression and availability do not necessarily lead to a shortening in telomeres, since telomerase has the ability to elongate the chromosomal telomeric ends, even if present in low quantities (51). Based on these findings, it may be suggested that the combination of chemotherapy and glucose restriction could lead to a decrease in both hTERT expression and telomere length in PTES cells, which in turn may result in a decrease in cancer cell immortalization.

Ca-125 is a key regulator of the metastasis of OC cells into the peritoneal cavity due to its strong affinity to mesothelin. Moreover, the sensitivity of OC cells to cisplatin has been narrowly linked to the expression of the surface marker Ca-125. Based on these facts, the changes in the expression of Ca-125 were investigated in both PTES and control groups. A decrease was observed in Ca-125 expression, which was lowest after treatment with fasting glucose concentrations. These 
findings are contradictory to those of previous studies stating that increased expression of the $\mathrm{Ca}-125$ gene leads to a decrease in the sensitivity of cells to genotoxic drugs, including cisplatin. Other studies have demonstrated that increased levels of Ca-125 at the end of the chemotherapeutic treatment are considered as a marker of poor prognosis and are associated with shorter progression-free and overall survival rates (52). The results of the present study revealed that the combination of chemotherapy with fasting glucose levels during the treatment resulted in the lowest $\mathrm{Ca}-125$ expression in all three types of PTES cells. Thus, this combination may contribute to improved survival rates in patients with OC, coupled with decreased levels of cancer cell immortalization due to the shortening of telomeres.

Based on the aforementioned results, telomerase and Ca-125 expression varied similarly after both short- and long-term treatments. To explain the low levels of Ca- 125 observed after 6 weeks of chemotherapy, the possible regulation of Ca- 125 gene expression by hTERT was investigated. In addition to its canonical function, one of the non-canonical functions of hTERT is its ability to regulate the expression of several genes in cancer (53). The decrease observed after the inhibition of hTERT by inhibitors (BIBR-1532, Costunolide and MST-312) and the silencing of the gene by hTERT siRNA demonstrated that hTERT regulates Ca-125 expression in OC. Moreover, the overexpression of Ca-125 after transfection of the PTES cells with pBabe-neo-hTERT verified the association between both proteins. A previous study reported that Ca-125 serum levels were higher in patients with telomerase-positive OC compared with patients with telomerase-negative OC (54). Moreover, a clinical study linking hTERT expression in ovarian biopsies and serum Ca-125 to the grade and stage of $\mathrm{OC}$ revealed a linear relationship between these two biomarkers (55). Therefore, it may be postulated that the decrease in hTERT expression in PTES cells may account for the decline in $\mathrm{Ca}-125$ expression and secretion.

Telomerase regulates the expression of several genes either directly or via its ability to control various signaling pathways, including the PI3K/Akt/mTOR pathway. Previous studies have highlighted the modulation of $\mathrm{Ca}-125$ expression by mTOR via the transcription factor c-MYC; therefore, the possible implication of the PI3K/Akt/mTOR pathway in the modulation of Ca-125 by hTERT was investigated. The results observed after the treatment with inhibitors of the pathway alone indicate a possible implication of this pathway in the regulation of Ca-125 expression. However, when combined with hTERT inhibitors, the treatment did not significantly potentiate the effect of the signaling pathway inhibitors when used as a mono-treatment. Thus, other signaling pathways may be involved in the regulation of $\mathrm{Ca}-125$ by hTERT. A possible pathway may be the nuclear factor- $\kappa \mathrm{B}$ pathway. In fact, mesothelin, a protein modulated by the activation of this pathway, interacts with Ca-125 to promote peritoneal metastasis (56).

To the best of our knowledge, the present study was the first to demonstrate the effect of chemotherapy combined with glucose restriction on the immortalization and metastasis of OC cells. When neoadjuvant or adjuvant chemotherapy was administered under fasting glucose conditions, telomerase expression was found to significantly decrease, thus contributing to the shortening of chromosomal telomeric ends, which in turn decreases the immortalization of cancer cells. Since telomerase serves an essential role in cisplatin resistance, this decrease may improve the response to chemotherapy. Moreover, this combined treatment was demonstrated to decrease Ca-125 expression and secretion, which could contribute to improved prognosis, since it is able to reduce the risk of peritoneal metastasis. Furthermore, since the combination of chemotherapy with hypoglycemic drugs is currently used in the treatment of various cancer types, including OC, the present study indicates a potential advantage in using this treatment regimen in both neoadjuvant and adjuvant forms.

\section{Acknowledgements}

Not applicable.

\section{Funding}

This study was funded by the Research Council of Saint Joseph University (grant no. FM 302).

\section{Availability of data and materials}

All data generated or analyzed during this study are included in the published article.

\section{Authors' contributions}

SA performed cell culture, cell treatments, RT-qPCR, ELISA and transfections, participated in the design of the study and wrote the manuscript. DA participated in the design of the study and manuscript. RT supervised and participated in the experimental work (cell culture and treatments), troubleshooting and data analysis. MDA made substantial contributions to analysis and interpretation of data. MM participated in the design of the manuscript. ENA and GH were responsible for the clinical data interpretation. GC made substantial contributions to interpretation of clinical data. GH designed the study, provided guidance and edited the manuscript.

\section{Ethics approval and consent to participate}

The present study was approved by the Ethical Committee of Saint Joseph University (Beirut, Lebanon).

\section{Patient consent for publication}

Not applicable.

\section{Competing interests}

The authors declare that they have no competing interests.

\section{References}

1. National Cancer Institute: Cancer Statistics. https://www.cancer. gov/about-cancer/understanding/statistics. Accessed May 18, 2017.

2. McLemore MR, Miaskowski C, Aouizerat BE, Chen LM and Dodd MJ: Epidemiologic and genetic factors associated with ovarian cancer. Cancer Nurs 32: 281-290, 2009.

3. Vajpeyi R: WHO Classification of Tumours: Pathology and Genetics of Tumours of the Breast and Female Genital Organs. J Clin Pathol 58: 671-672, 2005. 
4. Jelovac D and Armstrong DK: Recent progress in the diagnosis and treatment of ovarian cancer. CA Cancer J Clin 61: 183-203, 2011.

5. Kim A, Ueda Y, Naka T and Enomoto T: Therapeutic strategies in epithelial ovarian cancer. J Exp Clin Cancer Res 31: 14, 2012.

6. Argento M, Hoffman P and Gauchez AS: Ovarian cancer detection and treatment: Current situation and future prospects. Anticancer Res 28: 3135-3138, 2008.

7. Morgado M, Sutton MN, Simmons M, Warren CR, Lu Z, Constantinou PE, Liu J, Francis LL, Conlan RS, Bast RC Jr and Carson DD: Tumor necrosis factor- $\alpha$ and interferon- $\gamma$ stimulate MUC16 (CA125) expression in breast, endometrial and ovarian cancers through NFKB. Oncotarget 7: 14871-14884, 2016.

8. Norum LF, Erikstein B and Nustad K: Elevated CA125 in breast cancer--A sign of advanced disease. Tumour Biol 22: 223-228, 2001.

9. Cheng X, Gou HF, Liu JY, Luo DY and Qiu M: Clinical significance of serum CA125 in diffuse malignant mesothelioma. SpringerPlus 5: 368, 2016.

10. Namikawa T, Kawanishi Y, Fujisawa K, Munekage E, Iwabu J, Munekage M, Maeda $\mathrm{H}$, Kitagawa $\mathrm{H}$, Kobayashi $\mathrm{M}$ and Hanazaki K: Serum carbohydrate antigen 125 is a signifcant prognostic marker in patients with unresectable advanced or recurrent gastric cancer. Surg Today 48: 388-394, 2018.

11. Memar B, Aledavood A, Shahidsales S, Ahadi M, Farzadnia M, Raziee H, Noori S, Tayebi-Meybodi N, Amouian S and Mohtashami S: The Prognostic Role of Tumor Marker CA-125 in B-Cell non-Hodgkin's Lymphoma. Iran J Cancer Prev 8: 42-46, 2015.

12. Baalbergen A, Janssen JW and van der Weiden RM: CA-125 levels are related to the likelihood of pregnancy after in vitro fertilization and embryo transfer. Am J Reprod Immunol 43: 21-24, 2000.

13. Bon GG, Kenemans P, Dekker JJ, Hompes PG, Verstraeten RA, van Kamp GJ and Schoemaker J: Fluctuations in CA 125 and CA 15-3 serum concentrations during spontaneous ovulatory cycles. Hum Reprod 14: 566-570, 1999.

14. Das S and Batra K: Understanding the unique attributes of MUC16 (CA125): Potential implications in targeted therapy. Cancer Res 75: 4669-4674, 2015.

15. Hoogstad-van Evert JS, Maas RJ, Van der Meer J, Cany J, Van der Steen S, Jansen JH, Miller JS, Bekkers R, Hobo W, Massuger L and Dolstra H: Peritoneal NK cells are responsive to IL-15 and percentages are correlated with outcome in advanced ovarian cancer patients. Oncotarget 9: 34810-34820, 2018.

16. Su Y, Tatzel K, Wang X, Belt B, Binder P, Kuroki L, Powell MA, Mutch DG, Hawkins WG and Spitzer D: Mesothelin's minimal MUC16 binding moiety converts TR3 into a potent cancer therapeutic via hierarchical binding events at the plasma membrane. Oncotarget 7: 31534-31549, 2016.

17. He X, Wang L, Riedel H, Wang K, Yong Y, Dinu CZ and Rojanasakul Y: Mesothelin promotes epithelial-to-mesenchymal transition and tumorigenicity of human lung cancer and mesothelioma cells. Mol Cancer 16: 63, 2017.

18. Chanvorachote P, Luanpitpong S, Chunhacha P, Promden W and Sriuranpong V: Expression of CA125 and cisplatin susceptibility of pleural effusion-derived human lung cancer cells from a Thai patient. Oncol Lett 4: 252-256, 2012

19. Shukla SK, Gunda V, Abrego J, Haridas D, Mishra A, Souchek J, Chaika NV, Yu F, Sasson AR, Lazenby AJ, et al: MUC16-mediated activation of mTOR and c-MYC reprograms pancreatic cancer metabolism. Oncotarget 6: 19118-19131, 2015.

20. Victorelli S and Passos J: Telomeres and cell senescence - size matters not. EBioMedicine 21: 14-20, 2017.

21. Shay JW and Wright WE: Senescence and immortalization: Role of telomeres and telomerase. Carcinogenesis 26: 867-874, 2005.

22. Meng E, Taylor B, Ray A, Shevde LA and Rocconi RP: Targeted inhibition of telomerase activity combined with chemotherapy demonstrates synergy in eliminating ovarian cancer spheroid-forming cells. Gynecol Oncol 124: 598-605, 2012

23. Greider CW: Regulating telomere length from the inside out: The replication fork model. Genes Dev 30: 1483-1491, 2016.

24. Koh CM, Khattar E, Leow SC, Liu CY, Muller J, Ang WX, Li Y, Franzoso G, Li S, Guccione E and Tergaonkar V: Telomerase regulates MYC-driven oncogenesis independent of its reverse transcriptase activity. J Clin Invest 125: 2109-2122, 2015.

25. Zhu J, Blenis J and Yuan J: Activation of PI3K/Akt and MAPK pathways regulates Myc-mediated transcription by phosphorylating and promoting the degradation of Mad1. Proc Natl Acad Sci U S A 105: 6584-6589, 2008.
26. Zhang S, Li Y, Wu Y, Shi K, Bing L and Hao J: Wnt/ $\beta$-catenin signaling pathway upregulates c-Myc expression to promote cell proliferation of p19 teratocarcinoma cells. Anat Rec (Hoboken) 295: 2104-2113, 2012.

27. Aunoble B, Sanches R, Didier E and Bignon Y: Major oncogenes and tumor suppressor genes involved in epithelial ovarian cancer (Review). Int J Oncol 16: 567-576, 2000.

28. Vander Heiden MG, Cantley LC and Thompson CB Understanding the warburg effect: The metabolic requirements of cell proliferation. Science 324: 1029-1033, 2009.

29. Hanahan D and Weinberg RA: Hallmarks of cancer: The next generation. Cell 144: 646-674, 2011.

30. Ma Y, Wang W, Idowu MO, Oh U, Wang XY, Temkin SM and Fang X: Ovarian cancer relies on glucose transporter 1 to fuel glycolysis and growth: Anti-tumor activity of BAY-876. Cancers (Basel) 11: E33, 2018.

31. Fang S and Fang X: Advances in glucose metabolism research in colorectal cancer. Biomed Rep 5: 289-295, 2016.

32. Schroll MM, LaBonia GJ, Ludwig KR and Hummon AB: Glucose restriction combined with autophagy inhibition and chemotherapy in HCT 116 spheroids decreases cell clonogenicity and viability regulated by tumor suppressor genes. J Proteome Res 16: 3009-3018, 2017.

33. Wardi L, Alaaeddine N, Raad I, Sarkis R, Serhal R, Khalil C and Hilal G: Glucose restriction decreases telomerase activity and enhances its inhibitor response on breast cancer cells: Possible extra-telomerase role of BIBR 1532. Cancer Cell Int 14: 60, 2014.

34. Bast RC Jr, Hennessy B and Mills GB: The biology of ovarian caner: New opportunities for translation. Nat Rev Cancer 9: 415-428, 2009.

35. Gamarra-Luques CD, Hapon MB, Goyeneche AA and Telleria CM: Resistance to cisplatin and paclitaxel does not affect the sensitivity of human ovarian cancer cells to antiprogestin-induced cytotoxicity. J Ovarian Res 7: 45, 2014

36. Cawthon R: Telomere measurement by quantitative PCR. Nucleic Acids Res 30: e47, 2002.

37. Livak KJ and Schmittgen TD: Analysis of relative gene expression data using real-time quantitative PCR and the 2(-Delta Delta C(T)) method. Methods 25: 402-408, 2001

38. Rao X, Huang X,Zhou Z and Lin X: An improvement of the 2(-delta delta CT) method for quantitative real-time polymerase chain reaction data analysis. Biostat Bioinforma Biomath 3: 71-85, 2013.

39. Zhou M, Zhao Y, Ding Y, Liu H, Liu Z, Fodstad O, Riker AI, Kamarajugadda S, Lu J, Owen LB, et al: Warbug effect in chemosensitivity: Targeting lactate dehydrogenase-A re-sensitizes taxol-resistant cancer cells to taxol. Mol Cancer 9: 33, 2010.

40. Glasgow C, Pacheco-Rodriguez G, Steagall WK, Haughey ME, Julien-Williams PA, Stylianou MP, Gochuico BR and Moss J: CA-125 in disease progression and treatment of lymphangioleiomyomatosis. Chest 153: 339-348, 2018.

41. Liang C, Qin Y, Zhang B, Ji S, Shi S, Xu W, Liu J, Xiang J, Liang D, Hu Q, et al: Oncogenic KRAS targets MUC16/CA125 in pancreatic ductal adenocarcinoma. Mol Cancer Res 15: 201-212, 2017.

42. Muallem MZ, Braicu I, Nassir M, Richter R, Sehouli J and Arsenic R: ERCC1 expression as a predictor of resistance to platinum-based chemotherapy in primary ovarian cancer. Anticancer Res 34: 393-399, 2014.

43. Meads MB, Gatenby RA and Dalton WS: Environment-mediated drug resistance: A major contributor to minimal residual disease. Nat Rev Cancer 9: 665-674, 2009.

44. Bapat SA, Mali AM, Koppikar CB and Kurrey NK: Stem and progenitor-like cells contribute to the aggressive behavior of human epithelial ovarian cancer. Cancer Res 65: 3025-3059, 2005.

45. Kigawa J: New strategy for overcoming resistance to chemotherapy of ovarian cancer. Yonago Acta Med 56: 43-50, 2013

46. Zhao Y, Liu H, Liu Z, Ding Y, LeDoux SP, Wilson GL, Voellmy R, Lin Y, Lin W, Nahta R, et al: Overcoming trastuzumab resistance in breast cancer by targeting dysregulated glucose metabolism. Cancer Res 71: 4585-4597, 2011.

47. Guo XL, Ma NN, Zhou FG, Zhang L, Bu XX, Sun K, Song JR, Li R, Zhang BH, Wu MC and Wei LX: Up-regulation of hTERT expression by low-dose cisplatin contributes to chemotherapy resistance in human hepatocellular cancer cells. Oncol Rep 22: 549-556, 2009.

48. Boivin M, Lane D, Piché A and Rancourt C: CA125 (MUC16) tumor antigen selectively modulates the sensitivity of ovarian cancer cells to genotoxic drug-induced apoptosis. Gynecol Oncol 115: 407-413, 2009. 
49. Bonneau C, Rouzier R, Geyl C, Cortez A, Castela M, Lis R, Daraï $\mathrm{E}$ and Touboul C: Predictive markers of chemoresistance in advanced stages epithelial ovarian carcinoma. Gynecol Oncol 136: 112-120, 2015.

50. Zhang Z, Yu L, Dai G, Xia K, Liu G, Song Q, Tao C, Gao T and Guo W: Telomerase reverse transcriptase promotes chemoresistance by suppressing cisplatin-dependent apoptosis in osteosarcoma cells. Sci Rep 7: 7070, 2017.

51. Sotillo-Piñeiro E, Sierrasesúmaga L and Patiño-García A: Telomerase activity and telomere length in primary and metastatic tumors from pediatric bone cancer patients. Pediatr Res 55: 231-235, 2004

52. Tian C, Markman M, Zaino R, Ozols RF, McGuire WP Muggia FM, Rose PG, Spriggs D and Armstrong DK: CA-125 change following chemotherapy in prediction of treatment outcome among advanced mucinous and clear cell epithelial ovarian cancers: A gynecologic oncology group study. Cancer 115: 1395-1403, 2009.

53. Li Y and Tergaonkar V: Noncanonical functions of telomerase: Implications in telomerase-targeted cancer therapies. Cancer Res 74: 1639-1644, 2014
54. Sapi E, Okpokwasili NI and Rutherford T: Detection of telomerase-positive circulating epithelial cells in ovarian cancer patients. Cancer Detect Prev 26: 158-167, 2002.

55. Maraei AA, Hatta AZ, Shiran MS and Tan GC: Human telomerase reverse transcriptase expression in ovarian tumors. Indian J Pathol Microbiol 55: 187-191, 2012.

56. Bharadwaj U, Marin-Muller C, Li M, Chen C and Yao Q: Mesothelin confers pancreatic cancer cell resistance to TNF- $\alpha$-induced apoptosis through Akt/PI3K/NF- $\kappa \mathrm{B}$ activation and IL-6/Mcl-1 overexpression. Mol Cancer 10: 106 , 2011.

(i) $($ This work is licensed under a Creative Commons Attribution-NonCommercial-NoDerivatives 4.0 International (CC BY-NC-ND 4.0) License. 